\title{
Prevention of blindness from glaucoma using the King's College Hospital computerized problem orientated medical record
}

\author{
R. PI T T S GR I CK \\ Ophthalmic Department, King's College Hospital, London
}

The case for the problem orientated medical record (POMR) has recently been well presented by Cross (1974). As he says, even subspecialists cannot now cope with the information overload and the chronic glaucoma patient in particular is liable to suffer from neglect through lack of clarity in the records of tests and treatment. If deterioration in sight from glaucoma is to be prevented, these records must be followed after diagnosis at regular intervals for the rest of the patient's life and, as Cross concludes, "the provision of medical care can be fully as exciting as moonshots. .. . This will not, however, come about unless physicians and other health workers concentrate on form and feed-back so that it becomes second nature to them, as it is for the space-shot engineers who plot and guide the course of a missile. Computerization of the medical record is the ideal way to handle efficiently the information overload. Medical records for handling by a computer must be structured for entry." This has been the approach of the King's College Hospital Glaucoma Centre to the problem of glaucoma management with the aim of preventing blindness from this condition.

\section{The importance of glaucoma}

Glaucoma affects I per cent of the population over the age of 40 years, and more than half of these patients have chronic glaucoma which is so insidious in onset and progress that the patient usually remains unaware of deterioration of vision until this is far advanced. There are about 20,000 patients blind from glaucoma in England and Wales and much of this blindness could have been prevented by the application of existing knowledge. Glaucoma accounts for I 3 per cent of those registered blind and, as Sorsby has pointed out, "the available evidence suggests that more of the elderly blind remain unregistered than come to registration" (Sorsby, 1966).

More recent reports show little change in the incidence of blindness from glaucoma (Sorsby, 1972). In the case of the other main causes of blindness, retinal degeneration and diabetic retinopathy, it is clear, as Address for reprints: R. Pitts Crick, F.R.C.S., c/o Ophthalmic Medical Secretary, William Bowman Ward, Kings College Hospital, Denmark Hill, London, SE5 9RS
Sorsby says, that "no real progress is possible without a massive increase in our knowledge". On the other hand, much blindness from glaucoma can be prevented by the careful application of existing knowledge as outlined in a report of a personal series of $14 \mathrm{I}$ patients with chronic simple glaucoma closely followed in private practice over a period of 20 years and averaging 6 years of supervision (Pitts Crick, I 974a); none had become totally blind from glaucoma and only three became registered during a total of more than 800 patient-years of management. In these three cases, the condition was far advanced when the patient was first seen, and treatment was subsequently impeded for various reasons. The simple guiding principle in this series was the careful control of the intraocular pressure to the level necessary to prevent optic nerve damage for a particular eye in the individual patient as shown by the maintenance of the visual fields on regular examination. The assumption proved to be effective in this group, which suggests that many, perhaps most, of those who lose their sight because of chronic simple glaucoma do so from neglect. It is the object of the present study to test this hypothesis. It may be thought that this has already been done but, in fact, the difficulties of $(a)$ long-term surveillance, $(b)$ the determination of clear diagnostic criteria, and $(c)$ the accurate measurements of parameters have led to many unproven assumptions about the prognosis of glaucoma, most of them gloomy and engendering a dangerous pessimistic and fatalistic attitude to glaucoma which is not justified. It is proposed to study the reasons for the widespread neglect of patients with glaucoma and the remedy for this neglect which includes the means of earlier identification of the disorder followed by methods of surveillance using accurate recording, structured for the computer, with computer-aided analysis and follow-up for the remainder of the patient's life.

\section{Reasons for the present neglect of patients with} chronic glaucoma

The importance of improved management and the imperative need for the adoption of methods to achieve this have been repeatedly presented to the 
senior medical officers of the Department of Health, who have found a variety of reasons why they should not give any practical support. Consequently they must bear the responsibility for the continued lack of any general progress in this field. The neglect of patients with chronic glaucoma results from a failure to understand the basic principles of management and to act on them.

The practical reasons for this are:

(I) The condition is insidious so that loss of visual field is often already serious at the time of diagnosis. (2) Continuous supervision at regular intervals is essential, and often fails.

(3) Diagnosis and supervision involve the informed use of special apparatus.

(4) The object of therapy is the maintenance of the visual field and too frequently the visual field tests are carried out at infrequent intervals by inexperienced staff using different methods. It follows that the records are not comparable and feed-back is faulty, the information necessary for the intelligent adjustment of treatment to a changing situation being non-existent.

(5) The patient cannot co-operate in the very tedious management programme because of insufficient explanation and reassurance. As the treatment often seems to make vision more difficult at the outset and may be a little uncomfortable, it tends to be discontinued, and the patient may default, only to seek advice again much later when the visual fields are very restricted. Explanation to the patient requires time and effort but will help directly by relieving anxiety, which is so important a factor in chronic glaucoma, as well as by improving the patient's collaboration.

(6) We have also observed that, when patients have general illnesses, the ophthalmic treatment is frequently discontinued, even in a hospital, because of ignorance of the importance of continuous glaucoma therapy.

(7) The life-long nature of the follow-up means that patients accumulate in any good general ophthalmic department or glaucoma clinic; this makes it difficult to maintain a good service as their numbers propressively outstrip the ophthalmic facilities and the voluminous medical notes are incapable of interpretation, because of the absence or non-comparability of the necessary information or the lack of medical staff time to extricate it from a very large number of unstructured records.

\section{Measures adopted at the King's College Hospital Glaucoma Centre}

To improve the visual prognosis, the following measures have been adopted:

(I) Glaucoma records have been structured for entry so that they are suitable for computerization.
(2) The tests are carried out in a precise standardized manner.

(3) The findings have been designed to be numerically recorded.

(4) The records, which have been evolved during the last 5 years and tested for 4 years with modification, can be analysed by the King's College Hospital computer.

(5) It is planned that visual field results and other data will eventually be transmitted directly to a computer for analysis and comparison with previous findings. A Visual Field Computer and Automatic Transcriber is at present being developed at King's College Hospital Glaucoma Centre in association with the Applied Sciences Laboratory of the University of Sussex (Crick, Ripley, and Pitts Crick, 1974; Pitts Grick, 1974b).

(6) Manual methods of follow-up are necessary at present, but it is envisaged that attendance will also be computer-controlled to eradicate human error in follow-up, especially of "high-risk" patients.

(7) The organization of a large number of welldocumented patients with computer analysis was planned to improve clinical standards with a view to the prevention of blindness. It is clear at the same time that it gives an unlimited opportunity for clinical research which will be fully exploited as soon as funds are available. This is at present impossible, except on a very limited scale, through shortage of staff.

(8) Discussion with ophthalmic colleagues in the S.E. Thames Region, several of whom are keen to collaborate, suggests that the prospects are good for the establishment of a Regional Glaucoma Service on these lines.

(9) Identification of glaucoma at an early stage is envisaged by means of $(a)$ screening of sections of the population particularly at risk, and $(b)$ publicity to encourage an awareness of the potentially serious nature of chronic glaucoma and the good prospects if the condition is well managed.

\section{(a) SELEGTIVE SCREENING}

As the prevalence of glaucoma is too low for general population screening to be an economic use of medical resources at present (Hollows and Graham, 1966), there are three groups who would justify this:

(i) Relatives. Between 7 and ro per cent of firstdegree relatives of patients with chronic simple glaucoma also have this disorder. Close relatives should, therefore, be examined (Paterson, 196r ; Miller, r96r).

(ii) The aged. The incidence of glaucoma rises steeply in persons above retirement age, and an examination on retirement would be rewarding.

(iii) Motorists. In any case these should be given a 
simple visual field test, for which the automatic apparatus being developed with Sussex University would be suitable.

\section{(b) PUBLICITY}

The involvement of members of the medical, optical, and ancillary professions in the work of the glaucoma clinics by demonstrations and lectures emphasizing the significance of signs of the condition would improve early diagnosis. It is recognized that such activities would throw a heavy burden on busy eye departments, but their importance is such that they have already been initiated at King's College Hospital, though our facilities and staffing are quite inadequate

\section{Ophthalmological terminology}

The following definitions have been followed in compiling the clinical notes:

\section{(I) Glaucoma}

A state of glaucoma exists when the height of the intraocular pressure (IOP) is such that there is a failure of compensation by the ocular circulation and tissues. Chief among the effects of an uncompensated pressure is ischaemia of, or pressure on, the optic nerve fibres of the optic nerve head, which causes progressive optic nerve damage.

\section{(2) Intraocular Critical Pressure (IOCP)}

This is the level of the intraocular pressure above which the ocular circulation and tissues fail to adjust to the pressure, and the eyes suffer the changes of acute or chronic glaucoma.

\section{(3) Secondary glaucoma}

Secondary glaucoma is usually considered to be present when an intraocular pressure of more than $20 \mathrm{~mm} . \mathrm{Hg}$ is accompanied by an ocular disturbance which can reasonably be expected to have caused the raised pressure. It is necessary to recognize an arbitrary level of pressure in this case, because the effects of the disturbance, which may be traumatic, inflammatory, vascular, or toxic in nature, make it difficult to assess the critical pressure.

\section{(4) Pre-glaucoma}

When one eye has suffered angle closure and the condition of the fellow eye is judged to predispose to angle closure, the condition is described as "Preglaucoma" for classification purposes.

\section{(5) Primary chronic closed-angle (mixed) glaucoma}

Primary closed-angle glaucoma and primary openangle glaucoma are genetically, pathologically, and clinically two separate diseases with a common factor of a raised intraocular pressure. The tendency towards these two conditions may, of course, co-exist and cases of mixed glaucoma may be seen where the closure of even a small sector of the angle may lead to a raised intraocular pressure because the outflow efficiency of the remaining drainage mechanism is of a low order. Such patients are best classified as cases of primary chronic closed-angle glaucoma, but it is essential to appreciate their dual nature for a clear understanding of the situation.

\section{(6) Significance of the height of the intraocular pressure}

In some patients, the blood supply to the optic nerve head is inadequate, even in the presence of a very low intraocular pressure which results in essential ischaemic optic neuropathy, but in the great majority of eyes it is the height of the intraocular pressure which will determine the occurrence of progressive glaucomatous optic atrophy and loss of vision.

\section{(7) Optic disc appearances}

These are difficult to quantify. It must be emphasized that disc cups are often double, having an anterior and a posterior portion. The cup diameter used in the cup/disc ratio is that of the posterior part of the cup and the assessment of the sharpness of the edge of the cup refers to the anterior cup. The pallor described is the average colour of the disc between the rather indefinite circumference of the posterior cup and the disc margin. It will be noted that frequently the area between the margin of the disc and the edge of the anterior cup where nerve fibres overlie the intermediary glial tissue is paler than that between the two cups in which nerve fibres have changed direction and are passing backwards towards the lamina cribrosa. Asymmetry between the eyes of the cup/disc ratio by $0 \cdot 2$ is highly suggestive of chronic glaucoma.

Methods adopted in collaboration with the K.G.H. Computer Gentre

Visual acuity, tonography, gonioscopy, visual fields, and other data are standardized and recorded num-

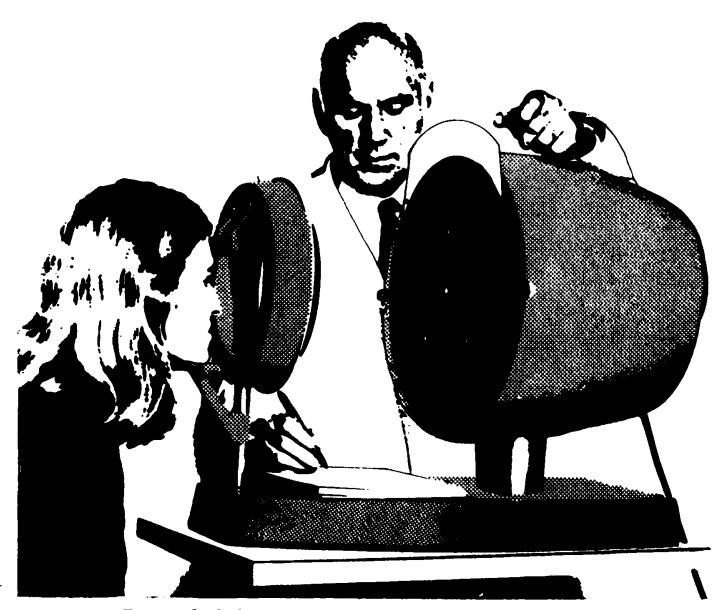

FIG. A Visual field analyser in use 
erically. The visual fields are tested and recorded as a parabolic projection (Pitts Crick, 1957) by a modification of the Visual Field Analyser introduced by Friedmann (1966), whose instrument has made an important practical contribution to the study of the visual fields (Fig. A, p. 238, and Fig. B, below).

\section{VISUAL FIELD CHART}

FOR PERIMETER TANGENT SCREEN AND FRIEDMANN ANALYSER (MONOCULAR)

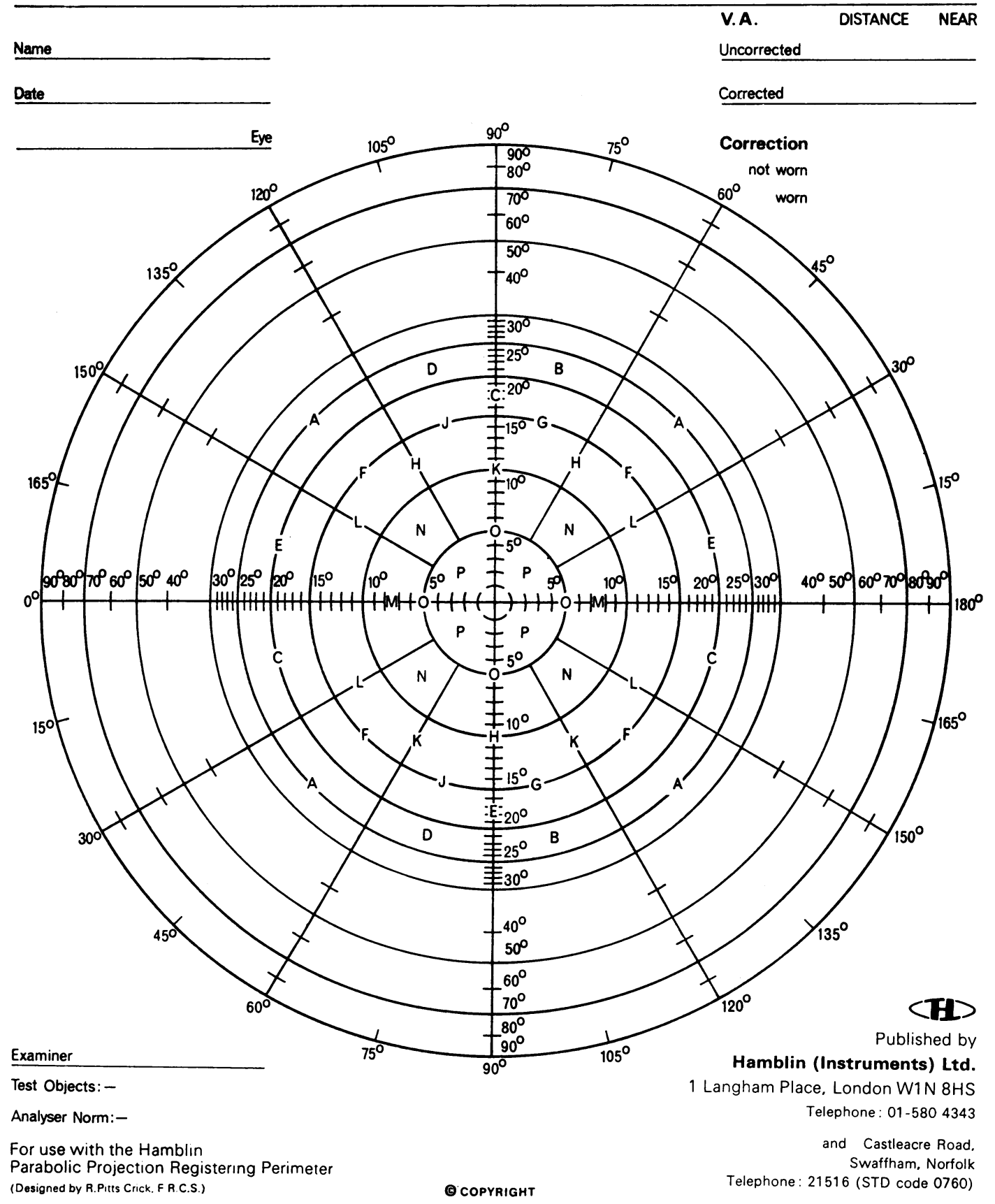

FIG. B Chart for recording visual field 


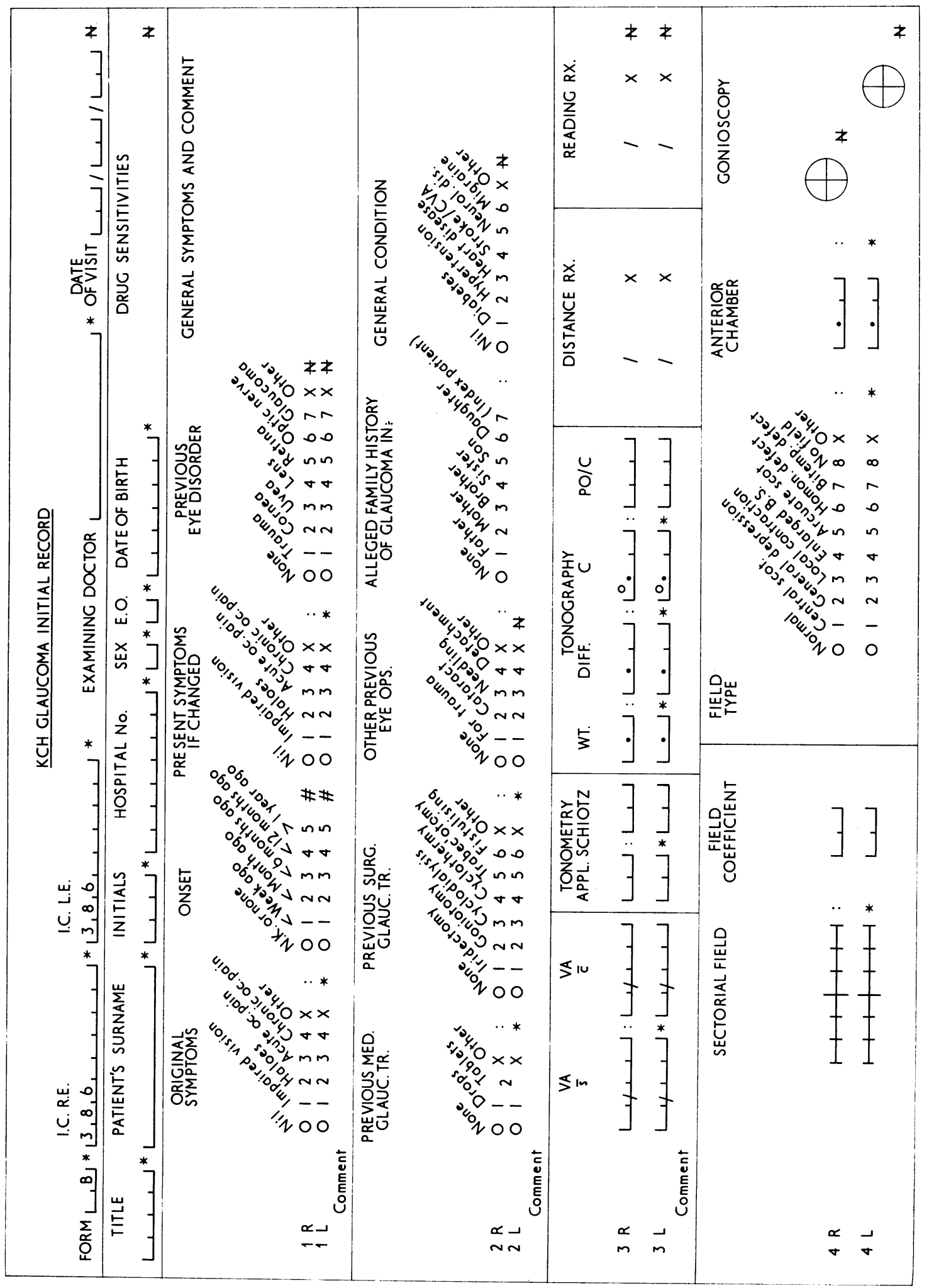




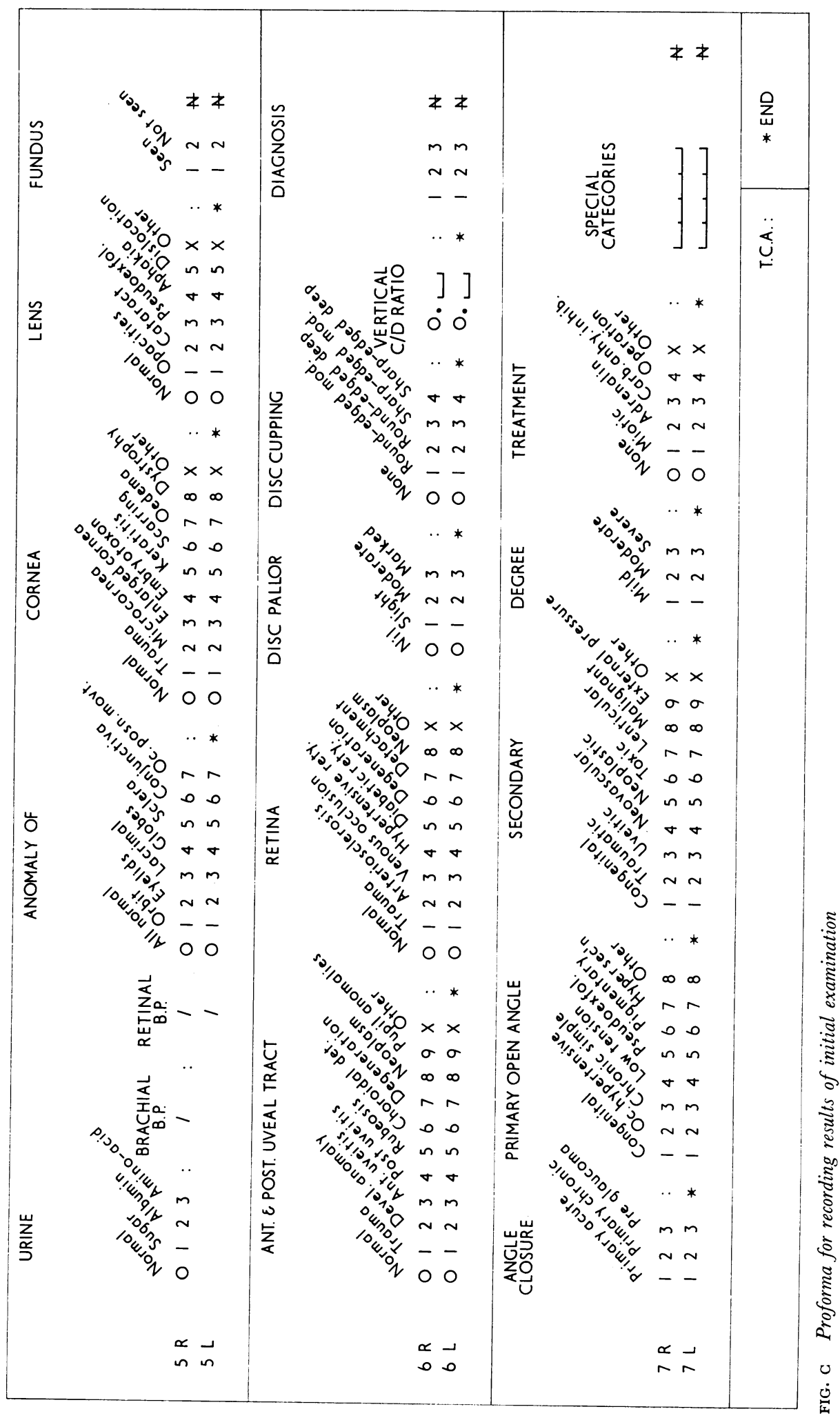




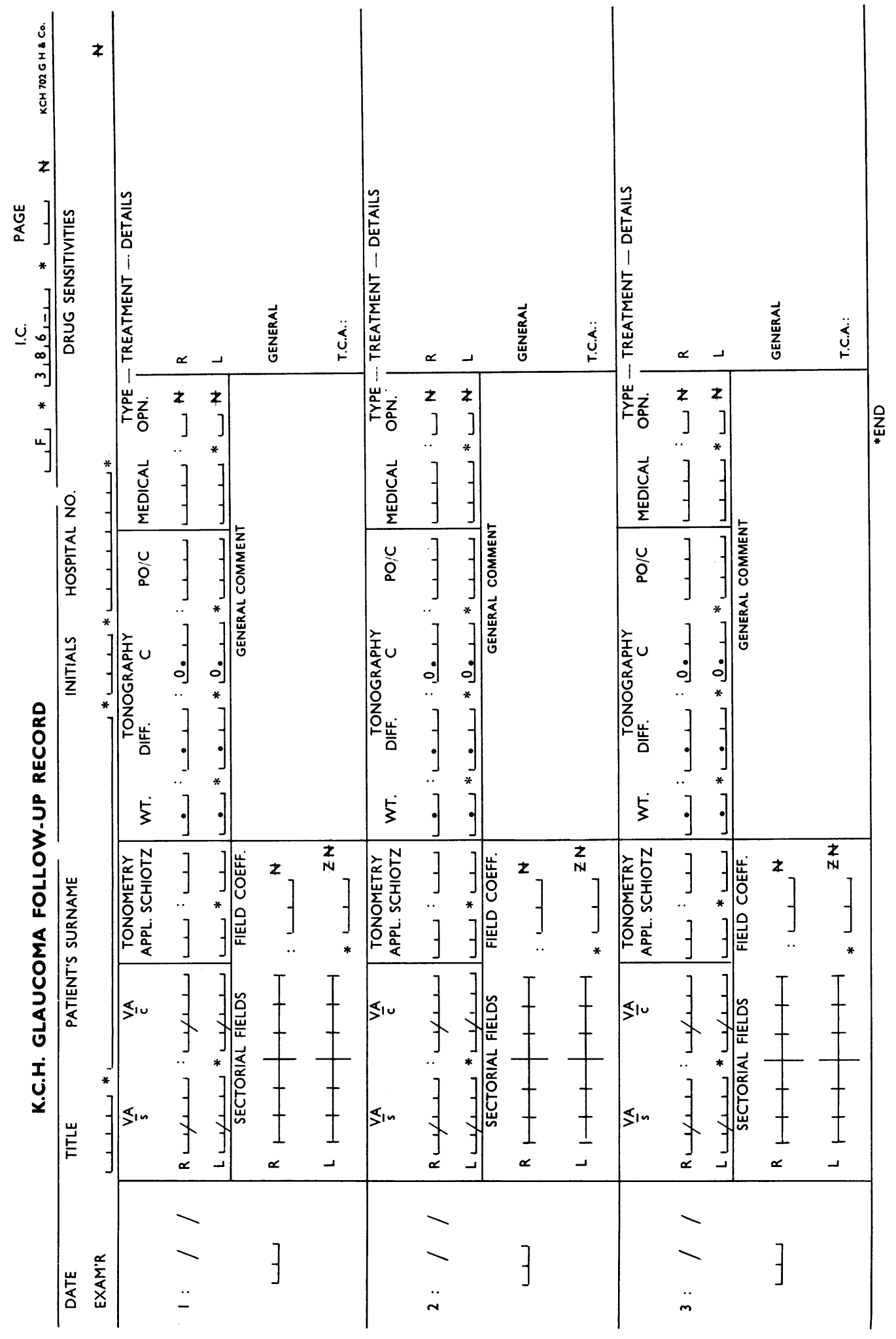

흥. 
The records are analysed by the K.C.H. Computer. Methods of analysis of data from specially designed clinical records have been in use for 4 years. It is planned that visual fields and other data will be transmitted immediately to the computer record for analysis and comparison with previous findings on a real-time basis.

Attendance records are being entered on a file for the 700 patients attending so that patients who have failed to attend are identified immediately. When necessary, patients and their doctors are reminded by letter that supervision is important, and if no response is obtained a Social Worker will investigate. Patients are also given a short pamphlet which explains the disorder in simple terms and encourages a good morale.

\section{The K.G.H. Problem Orientated Medical Record for Glaucoma}

It became clear that it was necessary to devise a system of note-taking which allowed flexibility so that it could be used as a general ophthalmic record and at the same time yield analysable data on the glaucoma aspect and matters relevant to it. The successful use of these forms involves disciplined co-operation from the medical staff and implies a carefully selected team, the members of which both understand and are in accord with the objectives of the project. The present format has been evolved gradually in the light of experience and, although still evolving, is now satisfactory.

The Initial Record (Fig. C, pp. 240, 241) summarizes the ophthalmic history and the findings of basic examinations which can usually be carried out at the first three attendances at the Glaucoma Centre and dated appropriately.

On the second and subsequent attendances, a section of the Follow-up Record (Fig. D, p. 242) is completed.The visual acuity, ocular tensions, and fields of vision are recorded in the same format as in the Initial Record, and this allows a rapid review of progress.

The "Instructions for the Use of the King's College Hospital Problem Orientated Glaucoma Records" (Fig. E, see pp. 244, 245) followed by members of the staff are self-explanatory, but it is desirable to comment on two points:

(a) In the interests of uniformity with other centres, the K.G.H. Classification of the Glaucomas (Table, see pp. $246,247,248$ ) has been developed on the basis of an International Classification of Disease, "Coding System for Disorders of the Eye" (SchappertKimmijser, 1968).

(b) All classifications are imperfect, and this applies particularly to the types of glaucoma. In order to promote understanding, the following definitions have been adopted (Table, pp. 246-248). Some sections may prove to have little validity or usefulness when the condition of glaucoma is more fully understood. Nevertheless, it is convenient for purposes of discussion to have certain clinical diagnoses identified if only to decide later that they do not justify separate grouping.

\section{OBJEGTIVES}

\section{(I) Social}

It is a matter of common observation that many patients lose their sight unnecessarily from glaucoma because of inadequate understanding and management of the disorder. As patients with glaucoma comprise one in seven or I3 per cent of the Registered Blind, there is great urgency for the adoption of methods such as those introduced at King's College Hospital. This would lighten an unnecessary burden on the social services and, even more important, prevent much personal misery.

\section{(2) Research}

A large group of glaucoma patients with computer recorded detailed documentation gives a unique opportunity for clinical research.

\section{(3) Assessment}

The assessment of any frequently recurring and numerically-recorded parameters in a very large number of patients is the type of medical clinical activity in which real-time computing techniques should bring added effectiveness to the work. Visual displays have already been designed, and their use suggests that further careful planning and education could make this a reality with new standards of efficiency.

\section{Summary}

(I) Chronic glaucoma accounts for a high proportion of blindness which is preventable and calls for energetic action because existing knowledge is not applied as it should be because of the indifference of the Department of Health and Social Security to the glaucoma problem.

(2) The condition is frequently insidious and advanced before being identified, and requires life-long supervision.

(3) When diagnosed, the management of glaucoma is frequently inadequate and intermittent for a variety of reasons.

(4) At King's College Hospital, a Glaucoma Centre has been initiated to supervise accurately and regularly a large number of glaucoma patients, assisted by numerical recording and computer analysis. While we are fortunate in having a computer 


\section{INSTRUCTIONS FOR THE USE OF K.C.H. GLAUCOMA RECORDS (FIG. E)}

The successful use of these forms involves disciplined co-operation. Data will be completely lost in some circumstances unless the following requirements are met. For general description please refer to "Prevention of Blindness from Glaucoma using K.C.H. computerized POMR".

\section{INITIAL RECORD}

1 (a) The K.C.H. Classification of Glaucomas Table based on the "Coding System for Disorders of the Eye 1968" will be completed before the record is transferred to the Computer. Space is provided only for the main numerical glaucoma diagnosis of each eye (see Paragraph 9). For secondary diagnoses the "Special Categories" are used.

(b) Examining Ophthalmologist-Full name and initials, e.g. J.C.ROBINSON

(c) All sections on the top two lines must be filled in. Please use CAPITAL LETTERS in the spaces where names are recorded.

2 (a) The patient's NAME and HOSPITAL NUMBER are essential.

(b) E.O. = ethnic origin Groups-Undetermined 0

$\begin{array}{ll}\text { Caucasoid } & 1 \\ \text { Mongoloid } & 2 \text { judged by inspection or other incidental information } \\ \text { Negroid } & 3 \\ \text { Other } & \text { X }\end{array}$

(c) SEX-M or F

(d) Drug sensitivities are important, and should be recorded.

3 Findings in lines $1 R$ and $\mathbf{L}$ are recorded by ringing the appropriate number.

(a) Original Symptoms

Those complained of when the patient first sought ophthalmic advice. These may have altered spontaneously, or as a result of treatment.

(b) Onset

Onset of earliest symptoms. Only one number should be ringed.

(c) Present Symptoms if Changed

This is the only field that can be omitted in lines $1 R$ and $1 L$ (if symptoms have not changed).

(d) Previous Eye Disorder

Further detail of the disorder can be written underneath or in the space for COMMENT.

4 ALL sections in lines $2 R$ and $2 L$ must be recorded.

FAMILY HISTORY

The Index Patient is the member of the family first examined at this centre.

5 (a) Standards of Visual Acuity At least one of the visual acuity entries should be recorded. While Snellen notation is used in the notes, the print-out will be in decimal form. The following are the equivalents:

$\begin{array}{lllllll}6 / 4 & 1.500 & 6 / 24 & 0.250 & 2 / 60 & 0.030 \\ 6 / 5 & 1.200 & 6 / 36 & 0.200 & 1 / 60 & 0.020 \\ 6 / 6 & 1.000 & 6 / 60 & 0.100 & \text { C/F } & 0.008 \\ 6 / 9 & 0.700 & 5 / 60 & 0.080 & \text { H/M } & 0.002 \\ 6 / 12 & 0.500 & 4 / 60 & 0.070 & \text { P/L } & 0.001 \\ 6 / 18 & 0.300 & 3 / 60 & 0.050 & \text { N/PL } & 0.000\end{array}$

(b) Decimal points are provided in the tonography sections, and it is important that no extra points are written in.

(c) Prescriptions for glasses $(R \times)$ should be written very clearly. Cylinders are recorded in + cyl. form. For emmetropes 0.00 / should be entered in the distance $R \times$. A degree sign should not be entered on the cylinder axis.

(d) Visual Field Recording Present lettering, as on the Friedmann Visual Field Analyser. New recordings not using vertical and horizontal meridian are in preparation. An example is given below of an upper arcuate scotoma. The field is divided into four quadrants and three zones of each quadrant. The neutral density filter value of each stimulus which is just seen is recorded. These values are averaged for each zone, and from these a Sectorial Field Score and a Visual Field Coefficient for the whole field can be simply calculated. 0.5 or more counts high. 


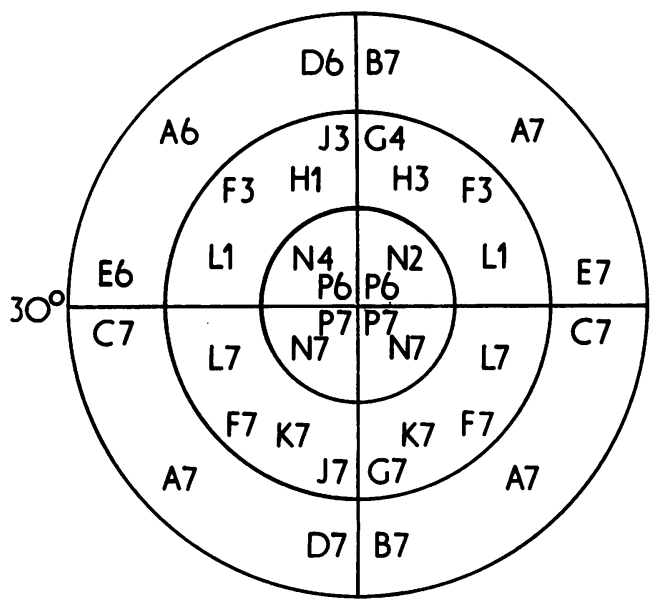

The Sectorial Field Score can be recorded thus:

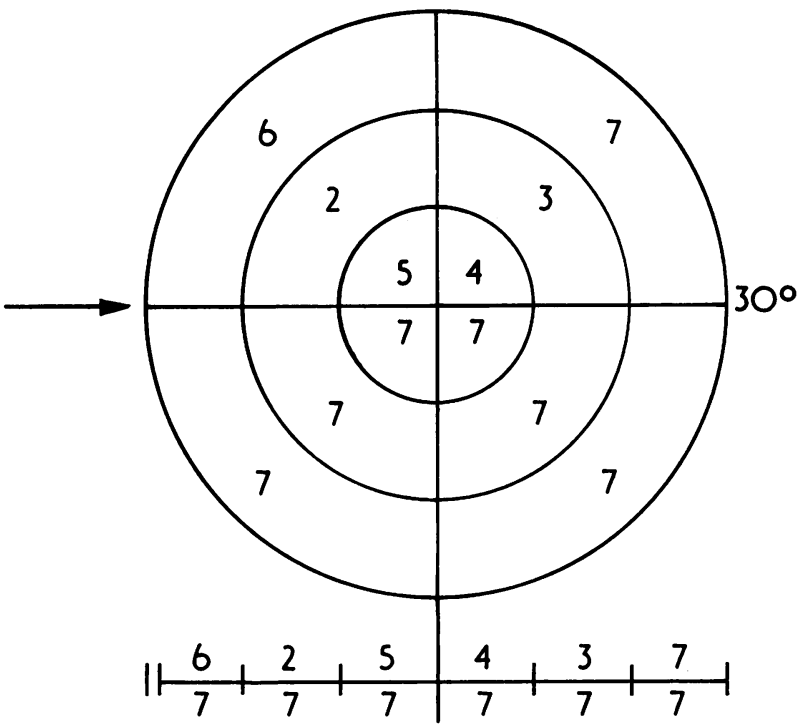

The Visual Field Coefficient is the total average field score to one place of decimals $\times 10$, in this case $10 \times 5 \cdot 8=58$. These findings have, of course, to be related to age and what can be expected in view of lens opacities or other pathology, but the visual field coefficient allows a rapid numerical comparison of a series of fields taken over a long period, and alerts the physician to the need for a more detailed assessment.

Single figure equivalents to neutral density filter value and colour code

\begin{tabular}{|c|c|c|c|}
\hline \multicolumn{2}{|c|}{ Green figures } & Red figures & Blue or black figures \\
\hline $\begin{array}{l}0.0 \\
0.0 \\
0.4\end{array}$ & $\begin{array}{l}\text { not seen }=0 \\
\text { just seen }=1 \\
\text { just seen }=2\end{array}$ & $\begin{array}{l}0.8 \text { just seen }=3 \\
1.2 \text { just seen }=4\end{array}$ & 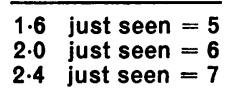 \\
\hline
\end{tabular}

The correct lenses should be worn in reading spectacles or by using the Lens Holder (Crick and Szymanski, 1975, to be published). Bifocals are unsuitable.

6 All sections on lines $4 R$ and $4 L$ must be filled in except ANTERIOR CHAMBER DEPTH and GONIOSCOPY, the absence of which does not prevent the transference to magnetic tape.

GONIOSCOPY Graded by two criteria (a) Angle appearance and (b) Iris configuration at four points-above, below, and at each side.

(a) Angle appearance Grades-0 Schwalbe's line not seen.

1 Schwalbe's line just seen.

2 Schwalbe's line and some trabeculum seen.

3 Scleral spur just seen.

4 Ciliary body seen.

(b) Iris configuration Grades-0 Extremely convex.

1 Moderately convex.

2 Slightly convex.

3 Flat.

4 Concave.

2-0 an intermediate
angle and extremely
convex iris-angle
closure possible.
$4-2$ a wide angle and
slightly convex iris-
angle closure unlikely.

Thus, the liability to closure may be appreciable in an angle graded 4-0, despite a good view of the ciliary body band being obtained. Space is provided for comments on pigmentation, synechiae, colobomata, iris configuration, etc.

7 SR and 5L All sections after the vertical line must be recorded. If fundus is recorded as "not seen", the rest of the record until diagnosis should be ignored.

8 GR and 6L Refer to "Note on optic disc appearances" in POMR description. All sections must be recorded except when fundus not seen. For this purpose "Ocular Hypertension" is classified as a form of "Glaucoma".

9 TR and 7L Glaucoma Diagnosis Diagnosis section should be ringed appropriately and the disease code recorded below and on the front of the notes. 
3860500 NOT GLAUCOMA

0510 Not glaucoma, but with family history of glaucoma

0520 Not glaucoma, but with positive provocative tests

5000 GLAUCOMA PRIMARY (not specified)

5100 PRIMARY DEVELOPMENTAL GLAUCOMA (buphthalmos, hydrophthalmos)

(a) pressure more than $20 \mathrm{~mm} . \mathrm{Hg}$

(b) coincident with developmental abnormalities of the mesoderm of the anterior chamber angle Includes:

5110 (1) Late developing infantile glaucoma

5120 (2) Glaucoma associated with: aniridia

$5130 \quad$ (3)

$5140 \quad(4)$

$5150 \quad$ (5)

$5160 \quad(6)$

$5170 \quad(7)$

$5180 \quad(8)$

Sturge-Weber syndrome

neurofibromatosis

Axenfeld's syndrome

Lowe's syndrome

Pierre Robin syndrome

(9)

Marfan's syndrome

microcornea

5200 OPEN ANGLE (Chronic Simple Glaucoma)
(a) Pressure more than $20 \mathrm{~mm}$. $\mathrm{Hg}$ or known to have been so
(b) Glaucomatous cupping of optic disc
(c) Visual field defect typical of glaucoma
(d) Angle of anterior chamber free of abnormal mesoderm and not obstructed by iris root
(e) Coefficient of outflow less than 0.50
(f) No excessive pigment deposits
(g) No pseudocapsular exfoliation

5210 Includes chronic simple glaucoma associated with Fuchs's dystrophy

5300 CLOSED-ANGLE ACUTE

(a) Pressure more than $20 \mathrm{~mm} . \mathrm{Hg}$

(b) Acute obstruction of angle of anterior chamber by root of iris

5310 Includes: Drug-induced pupil block and acute angle closure following provocative tests for angle closure and/or history strongly suggesting episodes of anterior chamber angle closure, the other eye not having had an angle closure episode.

5320 CLOSED-ANGLE PREGLAUCOMA

(a) The other eye has had acute closed-angle episode

(b) The configuration of the eye in question suggests a predisposition to angle closure and/or a history suggesting episodes of anterior chamber angle closure

5400 CLOSED-ANGLE CHRONIC

(a) Pressure more than $20 \mathrm{~mm} . \mathrm{Hg}$

(b) Chronic obstruction of part of the angle by the iris root either due to synechiae from previous attacks of acute closed-angle glaucoma or to apposition of iris root.

N.B. In some patients the distinction between closure of the angle by synechiae or by apposition of iris can be made either by the Zeiss Gonioscope lens or by deepening the anterior chamber surgically.

5500 PIGMENTARY

As for chronic simple glaucoma +

(e) Krukenberg spindle

5600 PSEUDOCAPSULAR

As for chronic simple glaucoma +

(e) pseudocapsular exfoliation

5700

5800 OCULAR HYPERTENSION

(a) Pressure more than $20 \mathrm{~mm}$. Hg on three occasions

(b) No glaucomatous field defect

(c) Angle of anterior chamber free of abnormal mesoderm

(d) no evidence of present or past angle closure

OTHER PRIMARY FORMS OF GLAUCOMA (specify)

contin. 
Table contin. 6000 SECONDARY DISORDERS OF INTRAOCULAR PRESSURE (not specified) and CERTAIN CONDITIONS
CONCERNED WITH GLAUCOMA NOT OTHERWISE CLASSIFIED

6100 SECONDARY CONGENITAL AND INFANTILE GLAUCOMA

(a) Pressure more than $20 \mathrm{~mm} . \mathrm{Hg}$

(b) presence of a congenital or infantile lesion (other than developmental abnormalities of the mesoderm of the anterior chamber angle) which can reasonably be expected to lead to a raised intraocular pressure (There may be an enlarged globe in this group) Includes:

6110

6120

6130

6140

6200

\section{LOW TENSION GLAUCOMA}

(a) Pressure never more than $20 \mathrm{~mm} . \mathrm{Hg}$

(b) Glaucomatous cupping of optic disc

(c) Visual field defect typical of glaucoma

(d) Angle of anterior chamber free of abnormal mesoderm and not obstructed by iris root
(2)

Intraocular neoplasm

Inflammation

Ocular trauma (a) Pressure of more than $20 \mathrm{~mm} . \mathrm{Hg}$

(b) Accompanied by an ocular lesion which can reasonably be expected to cause raised pressure includes:

(1) Trauma e.g.

(i) Epithelial ingrowth

(ii) Trauma to trabeculum and recession of anterior chamber angle

(2) Intraocular neoplasm.

(3) Neovascular formations (e.g.)

(i) Diabetic

(ii) Retinal vein occlusion

Vasculitis retinae
(i) Intumescent lens
(ii) Subluxated lens-includes: lens trauma homocystinuria spherophakia

(5) Essential iris atrophy

(6) Uveitis (e.g.)

(i) Acute

(ii) Granulomatous

(iv) Heterochromic cyclitis

(v) Bombé

(7) Malignant glaucoma-shallowing of anterior chamber and intractable raised intraocular pressure after operation for closed- angle glaucoma

(8) External pressure changes (e.g.)

(i) Increased episcleral venous pressure (carotico-cavernous fistula)

ensed retrobulbar pressure

Toxic effect on production and drainage of aqueous (e.g.)

(i) Steroids

Sanguinarine

rostaglandins

(v) Siderosis

(vi) Ammonia

contin. 
Table contin.

6400 ABSOLUTE GLAUCOMA (otherwise unclassified)

Any type of glaucoma which has proceeded to loss of perception of light

6410 Eye enucleated because of previous glaucoma

6500 HYPOTONY

Pressure constantly $6 \mathrm{~mm} . \mathrm{Hg}$ or less

6510 Essential Ischaemic Optic Neuropathy

As for low tension glaucoma, but $+(e)$ hypotony

6600 HYPERSECRETION GLAUCOMA

As for chronic simple glaucoma, except (e) coefficient of outflow more than 0.50

Note Intraocular pressures referred to are those obtained by using the Goldmann applanation tonometer

in the hospital, it is important to emphasize that the system can be operated without this facility, either by employing manual methods, or by batch processing. It would be both possible and desirable to organize recording and analysis on a regional basis in collaboration with hospitals wishing to participate.

(5) Attempts are being made to improve the early diagnosis of glaucoma by better communication between the hospital ophthalmologists, and other members of the medical, optical, and ancillary professions by lectures, demonstrations, and publications.

(6) Research is always hampered by the absence of factual knowledge. It is planned to use fully the opportunity for research into glaucoma made possible by this basic organization. At present, however, we consider it more important to carry out investigations into the problems of organizing the investigation, treatment, and follow-up of glaucoma patients than to embark on a few individual projects of research.
We are seriously hampered in our work by shortage of funds for staff and facilities, but we look forward confidently to the time when, with the essential support of the Department of Health, these methods will give us access to the facts of glaucoma, which besides enabling us to give a high standard of treatment to our patients, will give us an unprecedented opportunity of wide ranging research into all aspects of this important disorder.

I should like to express appreciation of the support of Ayerst Laboratories, the King's College Hospital Voluntary Research Trust, the Marley Company, and private benefactors in this work; of the help of the Directors of Computing, Mrs H. Blackmore and staff at King's College Hospital Computer Centre; of Professor John Anderson and my Ophthalmic Colleagues at King's College Hospital: of Mrs J. Williams, the Glaucoma Research Secretary; and of Mrs A. Warwick, Ophthalmic Medical Secretary.

\section{References}

CRIGK, J. G. P., RIPLEY, L. G., and GRIGK, R. P. (1974) "Proc. I int. Symp. on Visual Field, Marseille" (in press)

CRICK, R. PITTS (1957) Trans. ophthal. Soc. U.K., 77, 593

(1974a) Lancet, 1, 205

(1974b) "Proc. I int. Symp. on Visual Field, Marseille" (in press)

CROss, H. D. (1974) Brit. F. Hosp. Med., II, 65

FRIEDMANN, A. I. (1966) Ophthalmologica (Basel), r52, I

HAYREH, s. S. (1972) Brit. F. Ophthal., 56, I 75

hollows, F. C., and GRAham, P. A. (I966) "Glaucoma", ed. L. B. Hunt. Livingstone, Edinburgh

MILLER, S. J. H. (196I) Trans. ophthal. Soc. U.K., 81, 577

PATERSON, G. D. (I96I) Ibid., 81, 56I

SGHAPPERT-KIMMiJSER, J., COLENBrander, A., and FrANKen, S. (r968) "Coding System for Diseases of the Eye".

Karger, Basel.

SORSBY, A. (1966) "Incidence and Causes of Blindness in England and Wales, 1948-62". Reports on Public Health and Medical Subjects, No. I 14. H.M.S.O. London.

- (1972) Idem, I963-68, No. 128 